\title{
The Harmony of the Spheres from Pythagoras to Voyager
}

\author{
Dominique Proust \\ Observatoire de Paris \\ 92195 Meudon, 5 Place Jules Janssen, France \\ email: dominique.proust@obspm.fr
}

Abstract. We present the strong links between music and astronomy over 25 centuries.

Keywords. Astronomy, Music

\section{Introduction}

Astronomy is probably the most ancient of all the sciences, the celestial vault having attracted mans attention from very early on as much by its sumptuous beauty as by its mystery. Every day, the sun rose and set, the phases of the moon came in succession, and the same stars reappeared periodically. The persistence of these movements is at the origin of the laws on which were based those civilizations that followed the rhythm of the sky. We have to wait until the 6th century BCE for these first theories about observation to develop by associating celestial mechanics with music. The Ionians looked progressively at isolating natural phenomena in order to interpret them. For example, they noticed the tidal movement of the sea; they also knew the phases and movement of the moon. Was there a link between these phenomena? On the other hand, they tried to explain sonar phenomena such as resonance, echo, or the sounds produced by musical instruments such as flutes, strings and percussion. Did they believe the world was ruled by a unitary theory? From his research came the idea of the Harmony of the Spheres.

\section{The greek concepts}

Pythagoras (532-497? BCE), was probably the first person to associate strictly music and astronomy. The Pythagoreans were the first to put forward the hypothesis of the earth's roundness by considering geometric beauty. The fascination that numerical relationships in musical harmonies had on Pythagoras led him to try and explain the cosmos, which he considered to be a gigantic harmonic instrument of divine origin, in this way. According to Pythagoras, all the planets moved around the earth at constant speeds following orbits which obeyed the same numerical relationships as the scale, and giving off a sound:

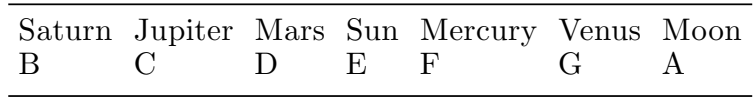

The analogy that seemed to exist between musical intervals and the spacing of the planets therefore represented for Pythagoras the secret of the world. One of the Pythagorean disciples, Philolaos of Croton (c 400) opened the way to heliocentric systems alongside 
the geocentric. Philolaos s ideas displeased Plato. He had presented his views on astronomy in Timeos in which he taught that the world, with its regular order, had started to exist by God s will, an infinitely good being. The planets were placed in order following 2 geometric progressions which formed an arithmetic musical scale of 4 octaves and a major 6th:

Moon Sun Phosporus (Venus) Hermes (Mercury) Mars Jupiter Saturn

Plutarch threw some more light on the harmonic knowledge of Plato in his De Musica, Chapter 22. In it, we find the main thrust of Plato s arguments in the tale of Pamphylios Er, right at the end of The Republic (book X, 614-621). This tale can be considered as the first true evocation of the harmony of the spheres. It also showed the order and distance of the planets. A century later in Alexandria, Alexander of Etolia (c $323 \mathrm{BCE}$ ) gave a technical description of the musical order of the cosmos. Pythagoras had his detractors who had moreover an arsenal of perfectly provable counter-arguments. Among them was Aristotle (On Heaven, II, 9) who affirmed that the universe was in the form of a sphere outside of which there was nothing. Aristotle vision of the world had a great success and came down through antiquity and the Middle Ages without being much modified. At the end of the 3rd century BCE, astronomical science used examples of geometric representations of celestial movements that had been studied in depth. This progress slowly influenced a Roman science still very much in its infancy. We have to wait for Cicero (106-43 BCE) who gives a description of the astronomical system then prevalent in a very clear expose in De Natura, book 2, chapters 40-41. The Pythagorean vision, which prevailed in Rome in the last century before our era, allowed the music of the spheres to have great acceptance once again. Cicero takes up the theme in the Dream of Scipio (Somnium Scipionis) which was immensely popular throughout the Middle Ages and which eventually became one of the sources of inspiration for a Mozart opera. This story is told in the Republic Book VI, XVIII. During the 2nd century of our era, astronomy developed in Alexandria through the work of Claudius Ptolemeus (100-170) whose model, built on the immovability of the Earth at the centre of the universe around which turned the planets and the stars, continued through the centuries until called into question by Copernicus by his heliocentric system. Besides his celebrated work, Almagest, Ptolemy drew up his dissertation on the Harmonies, in which the different musical theories were scrupulously analysed and compared with the harmony of the spheres along Pythagorean lines. Towards the end of the first century of our era, Nicomacus of Gerasia was very well known both in the world of mathematics and acoustics. His Arithmetica is the first work of its kind to have come down to us. In his Manual of Harmony, he studied the main questions about acoustics. He recalled that the names of the sounds are borrowed from the 7 stars that traverse the sky and revolve around the Earth and explained in details the music of the spheres:

\begin{tabular}{|c|c|c|c|c|c|c|c|}
\hline $\begin{array}{l}\text { planet } \\
\text { string } \\
\text { soundwave }\end{array}$ & $\begin{array}{l}\text { Moon } \\
\text { neta } \\
\text { tone }\end{array}$ & $\begin{array}{l}\text { Venus } \\
\text { paraneta } \\
\text { tone }\end{array}$ & $\begin{array}{l}\text { Mercury } \\
\text { trita } \\
\text { semi tone }\end{array}$ & $\begin{array}{l}\text { Sun } \\
\text { mesa } \\
\text { tone }\end{array}$ & $\begin{array}{l}\text { Mars } \\
\text { hypermesa } \\
\text { tone }\end{array}$ & $\begin{array}{l}\text { Jupiter } \\
\text { parhypata } \\
\text { tone }\end{array}$ & $\begin{array}{l}\text { Saturn } \\
\text { hypata } \\
\text { semi tone }\end{array}$ \\
\hline
\end{tabular}

Censorinus was a Roman astrologer who lived under Alexander Severus and his successors. In 238, he published a work De Die Natali. In chapter 13 on questions concerning the sky, stars and celestial measurement, he gave the following values for astronomical distances calculated in the form of musical tones: 


\begin{tabular}{ll}
\hline From the Earth to the Moon & one tone \\
From the Moon to Mercury & one semi-tone \\
From Mercury to Venus & one semi-tone \\
From Venus to the Sun & one and a half tone \\
From the Sun to Mars & one tone \\
From Mars to Jupiter & one semi-tone \\
From Jupiter to Saturn & one semi-tone \\
From Saturn to the Fixed Stars & one semi-tone \\
\hline
\end{tabular}

From the Earth to the Sun was three and a half tones, or a fifth, while from the Sun to the Fixed Stars was only two and a half tones, or a quarter. However, there are 6 tones, or an octave to go from the Earth to the stars. In his Banquet of the Wise, Atheneus of Naukratis (2-3rd century) took up the Pythagorean concept of the harmony of the spheres. Clement of Alexandria (?-214) was one of the Fathers of the Church who put forward the justification of universal harmony as an indispensable element of the Book of Genesis in his Sermons to the Greeks. The neoplatonic movement marked a real break with the essential meaning of the ancient philosophy. One of its most famous members, Plotinus (203-270) wrote 54 books which were grouped together as 6 Enneads and published by Porphyros of Tyre (232-304). Plotinus briefly called to mind in the Enneads $(\mathrm{IV}, 3,12)$ the passage in Plato s Republic regarding the harmony of the spheres and its importance in the recurrent order and perfection. Another great neoplatonic was Proclus who also wrote a Commentary on the Republic about the passage in which Plato talks about the harmony of the spheres. Boetius (480-524) was without doubt the most famous member of this school. In the 5 books which comprise De Institutione Musicae, he took up Nicomacuswritings which he completed with the works of Euclid and Ptolemy. Boetius used Pythagorass ideas, and obtained the following descending scale:

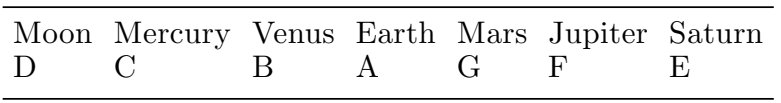

There can be found in the books of Martianus Capella (born in 470) a lot of information on celestial mechanics and the harmony of the heavens. These represent an important link between Plato and Copernicus by its attention to detail, in spite of errors and archaicisms. Gregory of Tours (538-594) witnessed the intensive use of Capella s writings in the schools and saw in the music of the spheres one of the manifestations of divine wisdom.

\section{The mediaeval period}

In the Middle Ages, the harmonic picture of antiquity changed considerably. The 9 strings of the celestial lyre increased to 15 to explain that beyond the planets were the Sky, Strength, Powers, Principalities, Dominations, Thrones, Cherubim and other Seraphim, ending at God himself. At the other extreme was the Earth which, being motionless at the centre of the world could not take part in the general harmony and kept silencium. Hildegarde von Bingen (1098-1179) was without doubt the most famous woman of her time. In her Divine Harmonies, an extract from Scivias (a.k.a. the way of the Lord), a book of visions written between 1141 and 1151, she described music as the surest way of understanding the cosmos and knowledge of Gods plans for finally entering the happiness of paradise. 
Throughout the Middle Ages, from Boetius, to Hucbald (840-930), Guy d'Arezzo (990?1050), Jean de Murs (Quadripartitum Numerum, 1319), Philippe de Vitry (1290-1361), the study of musical harmony was an integral part of mathematics and astronomy. Between 1320 and 1325, Jean de Murs and Philippe de Vitry worked on a new musical technique, L'Ars Nova, which was based on the division of binary or tertiary values and which they applied successfully to planetary movements in spite of numerous epicycles.

The first philosopher to make an association between polyphony and the cosmos was the Irishman, John Scotus Erigenus. His work, De Divisione Naturae (c 876) gave a technical description of organum. Erigenus claimed that polyphony gave an account of the beauty of the universe in an incomparable manner. Musical harmony was the reflection of the cosmic harmony of the music of the spheres, the Musica Mundana. The 12th century hymn, Naturalis concordia vocum cum planetis is the oldest known musical work inspired by the harmony of the spheres. We dont know the name of the composer; the manuscript uses a 2 octave planetary scale, the first consecrated to the stars and the second to the happy beings (cherubim, seraphim, etc). The scale that was used differs from Boetiuss:

\begin{tabular}{|c|c|c|c|c|c|c|c|c|}
\hline Heaven & Saturn & Jupiter & Mars & Sun & Venus & Mercury & Moon & Earth \\
\hline A & & & & & & & & silencium \\
\hline
\end{tabular}

Celestial harmony is one of the main themes running through Paradiso, the 3rd book of the Divine Comedy by Dante Alighieri (1265-1321). In Paradiso, Dante, distraught by the death of his beloved Beatrice, wanted to show her triumphant in eternal happiness. To get there, the poet undertakes like Er (Plato) and Scipio junior (Cicero), a voyage of discovery around the nine spheres of the heavens, which are driven by the angels, in order to reach the firmament.

The fundamental key of the mediaeval cosmic order can only be found in perfect harmony which at once ensures the coherence and the beauty of nature. Without it, music cant exist because harmony is the essence of organized sound. Armed with this evidence, the intellectuals from the Middle Ages to the Renaissance tried to associate as strictly as possible the cosmos and music in order to show their perfect symbiosis and to proclaim the supreme order made by the Creator. Gauthier of Metz wrote around 1245 the first encyclopedia in French l'Image du Monde (the Picture of the World). Composed in verse, it presented itself as a biblically inspired cosmography in which the author mixes learnedly the themes of unity and musical harmony with the system of the worlds. Roger Bacon (1214-1294) was not happy with the Ptolemaic system and showed up all its weaknesses, while associating it with the movement of the stars following the principles put forward by the musici, the musical theorists of the Middle Ages.

\section{The Renaissance}

During the Renaissance, the ideal equilibrium between harmony and physics became untenable mainly because of the number of spheres and epicycles necessary to explain the planetary movements. The old theory of Philolaos, which had the Earth as a sonorous and moving star, came back into fashion and was taken up by in 1543 by Copernicus in his work De revolutionibus orbium coelestium. It evoked the harmony of the spheres in chapter 10 of the first book to justify his proposition and concluded that the Earth and the planets turned around some point in space, probably distinct from the Sun. In Italy, Leonardo da Vinci (1452-1519) devoted a chapter of his work in order to know if the friction of the heavens makes a sound or not and putting forward some arguments to refute 


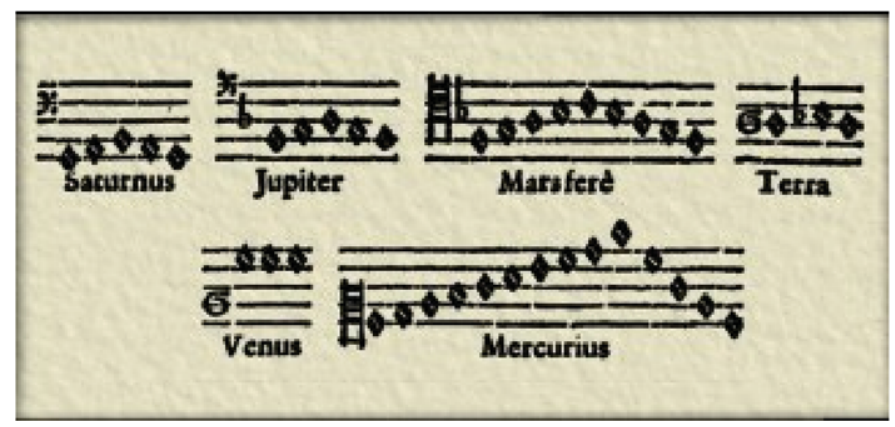

Figure 1. The planets music, according to Kepler's Harmonices Mundi (1619).

the music of the spheres. Pierre de Ronsard (1524-1585) evokes the celestial harmony of the heavens, giving this phrase a double meaning, in his first book of Hymns, Du Ciel, 1555. This was also one of the preoccupations of Doctor Faustus in the tragedy written in 1588 by Christopher Marlowe (1564-1593). William Shakespeare (1564-1616) has Lorenzo explain while talking to Jessica why mortals do not hear the supreme harmony (Merchant of Venice, Act 1, scene 5).

Johannes Kepler (1571-1630) discovered that he could associate the planets with regular polyhedrons. The number of polyhedrons being equal to the number of intervals between the different planets, Kepler placed successively each of the polyhedrons between their orbits: the octahedron between Mercury and Venus, the icosahedron between Venus and the Earth, the dodecahedron between the Earth and Mars, the tetrahedron between Mars and Jupiter and finally the cube between Jupiter and Saturn, and moreover, for Kepler, it worked (give or take a bit). Delighted with his discovery, the first steps towards a universal geometric order, the astronomer published his results in 1596 in his Mysterium Cosmographicum. His work started to become know in Europe but Kepler wanted to perfect it under the guise of a unified model by associating geometry and music through musical intervals, thirds, fourths, fifths etc to the diameters of orbits. According to Kepler, the angular speed of each planet in its movement around the sun, measured in seconds of a degree by day gave the number of vibrations of each tone. He thus arrived in this way in obtaining the fundamental melody of each of the planets (see Fig. 1).

The book Harmonices Mundi containing the results of his works on harmony was published in 1619. It established that the laws of music are present throughout nature, that harmonies are the result of the reality of these laws and mans capacity to hear them, and finally that they work implicitly to serve the work of the Creator.

Some years after Keplers publication, Galileo (1564-1642) became interested in trying to establish a link between his astronomical preoccupations and his research into music. His father, Vicenzo Galilei (1520-1591) was one of the most eminent members of the Florentine school of music, both Frescobaldi and Vivaldi being inspired by his compositions. Besides the celebrated astronomer, Vicenzo Galilei had another son, Michelagnolo (1575-1631) whose compositions for lute included in the collection Il Primo Libro dintavolatura di Lioto show boldness in a style made totally revolutionary by its dissonance and rhythmic freedom. Giambattista Marino (1569-1625), known as Cavalieri, edited in 1623 a gigantic poetic document, Adonis, which glorified the arrangement of the cosmos in a vast machine, the work of a demigod, whose order and harmony were identical to those of a clock or an organ.

Organist, lutenist and composer, Vicenzo Galilei s teacher was Zarlin (Gioseffo Zarlino 1517-1590), a composer and musical theorist, and choirmaster at St Marks in Venice. 
Zarlin was above all known for the elaboration of a tonal scale based on a pure diatonic system and arithmetical proportions. In his Institutioni Harmoniche (1558), he took up the dogma of the harmony of the spheres. In his Dimostrationi Harmonische of 1571, he established relationships between the sound-waves of the planetary scale, which he called monochords, the four elements and the nine muses. Zarlin s work was taken up and completed in 1617 by Robert Fludd in his Ultriusque Cosmi, by Martin Mersenne in 1636 in his Harmonie Universelle and in two major works by Athanasius Kircher (1601-1680) Musurgia Universalis (1650) and his Itinerarium exstaticum coeleste (1656). Abraham Bartolus published in 1614 his Musica Mathematica containing a relationship between the planetary scales and the letters of the alphabet. The planetary scales of Bartolus, Zarlin, Fludd and Mersenne were as follows:

\begin{tabular}{|c|c|c|c|c|c|c|c|c|c|c|c|}
\hline Left & Right & High & Low & Earth & Moon & Mercury & Venus & Sun & Mars & Jupiter & Saturn \\
\hline A & B & $\mathrm{C}$ & D & $\mathrm{E}$ & $\mathrm{F}$ & G & A & B & $\mathrm{C}$ & $\mathrm{D}$ & $\mathrm{E}$ \\
\hline A & B flat & $\mathrm{C}$ & D & $\mathrm{E}$ & $\mathrm{F}$ & G & A & B flat & $\mathrm{C}$ & D & $\mathrm{E}$ \\
\hline
\end{tabular}

Table 1. Bartolus cosmic scale

\begin{tabular}{|c|c|c|c|c|c|c|c|}
\hline $\begin{array}{l}\text { Nete } \\
\text { C }\end{array}$ & $\begin{array}{l}\text { Moon } \\
\text { B }\end{array}$ & $\begin{array}{l}\text { Mercury } \\
\text { A }\end{array}$ & $\begin{array}{l}\text { Venus } \\
\mathrm{G}\end{array}$ & $\begin{array}{l}\text { Sun } \\
\text { F }\end{array}$ & $\begin{array}{l}\text { Mars } \\
\mathrm{E}\end{array}$ & $\begin{array}{l}\text { Jupiter } \\
\text { D }\end{array}$ & $\begin{array}{l}\text { Saturn } \\
\text { C }\end{array}$ \\
\hline
\end{tabular}

Table 2. Zarlin cosmic scale

\begin{tabular}{|c|c|c|c|c|c|c|c|c|c|c|c|}
\hline $\begin{array}{l}\text { Earth } \\
\text { G }\end{array}$ & $\begin{array}{l}\text { Air } \\
\text { A }\end{array}$ & $\begin{array}{l}\text { Fire } \\
\text { B flat }\end{array}$ & $\begin{array}{l}\text { Water } \\
\mathrm{C}\end{array}$ & $\begin{array}{l}\text { Moon } \\
\text { D }\end{array}$ & $\begin{array}{l}\text { Mercury } \\
\mathrm{E}\end{array}$ & $\begin{array}{l}\text { Venus } \\
\mathrm{F}\end{array}$ & $\begin{array}{l}\text { Sun } \\
\text { G }\end{array}$ & $\begin{array}{l}\text { Mars } \\
\text { A }\end{array}$ & $\begin{array}{l}\text { Jupiter } \\
\text { B flat }\end{array}$ & $\begin{array}{l}\text { Saturn } \\
\text { C }\end{array}$ & $\begin{array}{l}\text { Fixed } \\
\text { D }\end{array}$ \\
\hline
\end{tabular}

Table 3. Fludd and Mersenne cosmic scale

As regards acoustical sounds, Zarlin also had the young Galileo as a pupil. This latter returned to the sources of Pythagoras and published in 1636 his Dialogue concernant deux nouvelles sciences, and established a link between musical intervals and the number of vibrations per second. He greatly benefited from his fathers experience having noticed over a number of years how the length of an organ pipe determined the pitch of the sound. Many came to visit Galileo, among them the poet John Milton (1608-1674) in 1638. He evoked moreover the harmony of the spheres in his Arcadia. Among the dramatists and poets of Jacobean England, John Dryden (1613-1700) also associated musical and celestial harmonies. At the same time, Claudio Monterverdi (1567-1643) put to music the light of the stars in a madrigal in his seventh book, Al lume de stelle. In the Netherlands, Christian Huygens (1629-1695) was very active in many branches of science: astronomy, geometry, infinitesimal calculus, optics as well as music. In 1691, he defined in his Letter concerning the harmonic cycle a system which divided the octave into 31 equals tones, each of them called sharp in which the different major and minor relationships were included. He composed several pieces based on this pseudo-tempered scale which had some success in his home country. In France, Marin Mersenne (1588-1648) translated Galileo $\mathrm{s}$ books and continued his work on the vibrations of strings. He published his Traite $d$ harmonie universelle in 1627, then $l$ Harmonie Universelle in 1636 which was a real compendium of all knowledge accumulated to that date in acoustic and musical matters. Besides his interest in mathematics, Mersenne was a keen astronomer and included in his books designs for telescopes side by side with his musicological analyses, thus bringing up to date the question of the harmony of the spheres. 


\section{The age of the Enlightenment}

The vision of the universe in the 18th century or the Age of the Enlightenment is strictly linked to the precious ideas of order and harmony, issues now long gone. To this wellordered picture of the world however was grafted a metaphysical cosmos in which the link between nature and the divine played a major role. This new metaphysical cosmology saw the light of day in the years 1730-1750. Isaac Newton was one of the principal founders of modern science by the revolution that he introduced into mathematics, mechanics, astronomy and optics. He set out in his Principia published in 1687 the laws of motion and gravity. He was nearly as interested in music as well. In the year 1666, he circulated in Cambridge a brief treatise on musical theory in which he used logarithms to calculate the relationship of sounds in a series of 18 scales from Greek modes and oriental tradition. Moreover, he had managed with the help of a prism to split sunlight, and he associated the 7 notes of the scale with colours that he obtained from the spectrum following a theory which wouldn't set light to the world of physics but which did inspire a number of musicians. Newton's music of the spheres was thus enriched with a new tripartite framework which unified the 7 planets, the 7 notes and the 7 colours. The new basis given by Newton to the music of the spheres by the association of the movement of the planets by means of gravity, music and the properties of light, was accompanied by a gushing forth of ideas, a real fermentation of ideas, from the young cosmologist. The word cosmology itself only appeared in 1731 in the Cosmologia Generalis by Christian Wolff (1679-1754). However, we have to wait for Thomas Wright's (1711-1786) Theory of the Universe to find the first dynamic interpretation of our Milky Way. Later, he generalised this idea in glimpsing the idea of a universe comprising several system analogous to the Milky Way. These are the Universe Islands of his New Theory of the Universe published in 1750. These theories are further developed in the Lettres Cosmologiques (1761) by Jean Henri Lambert (1728-1777) in which he suspected that the universe is strewn with Milky Ways similar to our own, using several teleological principles including the fullness, diversity and harmony emanating from tonal scales. From this research to the numerous facets on the order and harmony of the world, the new-born cosmology gradually installed itself into a metaphysical and quibbling language that meandered on interminably. The conjectures of Maupertuis, Wright and Lambert were taken up by Emmanuel Kant (17241804) who published in 1755 in his Theory of the Heavens a more complete explanation, All these researches, digressions and speculations sowing the foundations of cosmology were going towards a consolidation of universal harmony. Kant intervened to put some order into this theoretical mess but left music to one side in spite of Newton's work in discreetly associating movement, sound and colour in the harmony of the spheres.

Bach, Mozart and Haydn turned out to be illustrators of sound. In spite of the contradictions and quarrels that they aroused, cosmological ideas in the 18th century were the extraordinary current fruits of thought which were circulating across Europe and which came together in the princely courts where astronomers such as Maupertuis and Lambert crossed paths with musicians such as Johann Sebastian Bach and his sons. The General History of Nature and Theory of the Heavens by Kant was dedicated in 1755 to king of Prussia Frederick II (1712-1786), as was Bach's Musical Offering in 1748.

Johann Sebastian Bach (1685-1750) was one of the greatest musicians of all time. His compositions are real monuments which call to mind immediately the concepts of architecture and harmony. However, he only alluded to the astronomical heavens by using the old theme Wie schon leuchtet der Morgenstern (How brightly shines the morningstar). This melody can be found in several of his works. Bach goes no further than Luther in his astronomical observations which hardly seem to have interested him if you 
take a close look at his work. The paradox however resides in the fact that his work is constantly being cited whenever notions of architecture, waves and harmony are brought up. Bach got his inspiration from the well-known masters of the day such as Dietrich Buxtehude (1637-1707). A native of Denmark, he was very much interested in astronomy having been organist at Elsinore close to the old observatory of Tycho Brahe. Among this numerous compositions for organ, Buxtehude wrote a Passacaglia comprised of four musical sections analogous to the four phases of the moon in its 28 day cycle.

In 1788, a major discovery strengthened the concept of the music of the spheres in the solar system and its consequences allowed the working out of cosmogonic models, the most well-know of which is Laplace's. In Germany, Johann Elert Bode (1747-1826), the director of the Berlin Observatory, published an empirical law which had considerable success because it at long last showed that mathematical order ruled the world. According to his theory, the distance from the planets to the Sun can be expressed as a geometric progression. We find the resurgence of a harmony of the spheres in the Masonic tide in which Wolfgang Amadeus Mozart (1756-1791) was one of the players. Across three of his operas, he developed his harmonic conception of the cosmos: Il sogno di Scipione, which takes up Cicero's tale, Don Giovanni and the Magic Flute. In the world of science, cosmological theory, stripped of its cumbersome metaphysics, took the form of a natural religion whose principal protagonist was William Herschel.

William Herschel (1738-1822) was one of the key figures in the dual world of music and astronomy. His observations played a critical role in the then current cosmology of the Age of Enlightenment. He was also a talented musician, playing the oboe, violin and organ. His musical output was as follows: 24 symphonies (1760-1764), 12 concertos for oboe, violin, viola (1759-1764), 2 concertos for organ, 6 sonatas for violin, cello and keyboard etc. His vocal work included a Te Deum, a number of psalms, some motets and antiphons. His keyboard pieces were collected in several volumes, to be played on either the organ or the harpsichord. Herschel was a great friend of Johann Christian Bach (the last son of Johann Sebastian) as well as with Charles Burney (1726-1814) who, besides his activity as organist, travelled musical Europe and devoted himself to amateur astronomy. Besides a number of incredible observations of the moon, sun, planets and stars, the most impressive works of Herschel were to have observed and catalogued a total of 2451 nebulosa, stellar masses, diffuse blemishes or what you will. Thanks to this Construction of the Heavens, his fame as an astronomer spread throughout Europe. On his last visit to London in 1792, Joseph Haydn (1732-1809) paid a long visit to Herschel. Haydn didn $t$ fail to immerse himself in the cosmological theories of Lambert and Kant about the origins of the universe. In his oratorio The Creation composed only five years after Haydn's celebrated visit to Herschel, the famous passage Es ward Licht (Let there be light) is marked with a double forte following a passage which is entirely pianissimo; Light shone and the Universe began. Herschel's cosmology excluded accepted propositions and speculations beyond the possibilities of his telescope. Astronomical deductions only existed through his questioning what he had seen in terms of the condensing and fragmentation of matter, William Herschel's remarkable contribution to cosmology rests on his tenacity in observing which was far from any dogmatic context; he observed in the same way that he played scales on the organ in order to be in harmony with the universe.

\section{From romanticism to the contemporary times}

The 19th century which was marked by the romantic movement for its first half completed the radical transformation of the vision of the world into two dominant directions 
without going in for long cosmological discussions. Celestial harmony could be generalised as the ensemble of the objects in the universe, but now not so much as a relationship of harmony as of hierarchy in which each celestial body was part of a structure overlapping in the structure of a higher order. Romantic musicians continued to show an interest in the cosmos. The return to the origins of ancient Greece and the exacerbation of romantic sentiment led them to resuscitate the ancient myths of the sun and moon. These gave rise to nights and nocturnes lit up with romantic passion, for instance the piano music of Frederic Chopin, while there also developed an esoteric, mysterious and somewhat, in its own way, ominous tradition such as the strange work by Carl Orff (1895-1982), Der Mond (the Moon). The sun itself became a special star which offered inspiration to a number of composers from Mesomede of Crete to Louis Vierne (1870-1937), organist of Notre Dame de Paris: Hymne au Soleil as well as a Clair de Lune.

The 19th century was an extraordinarily fecund period in which musicians and scientists met each other in an exceptionally intellectual melting pot just as had happened in the Age of Light. Aristide Cavaille-Col built organs with the effective support of Le Verrier and collaborated with Foucault; Jules Massenet observed the heavens between two of his compositions and Camille Saint Saens was a frequent visitor to Paris observatory. Max Reger (1873-1916) used the old hymn Wie schon leuchtet der Morgenstern to compose one of his finest organ works. In Russia, Alexander Borodin (1833-1887) composed music of extreme refinement which was characterised by its clear and scintillating colour. A renowned chemist, he knew how to ally the properties of matter to the harmonies of his symphonies and his string quartets. In England, Gustav Holst (1874-1923) studied astronomy in order to understand the new theory of the space-time continuum that Einstein was developing. However, his tone poem The Planets (1914-16) resumed a relationship with the traditions of the ancients in finding traditional themes for each planet.

Scientific progress at the end of the 19th and beginning of the 20th centuries rapidly brought into the full glare the importance of the laws of physics up until then only suspected or scarcely glimpsed such as thermodynamics or the study of oscillatory phenomena. The composite aspects of wave theory favoured the appearance of a contemporary musical language, with the physicist coming to the rescue of the musician. Igor Stravinsky s (1882-1971) Rite of Spring in which new sounds reverberate, is moreover a contemporary of the beginnings of relativity. The new frontiers of astronomy across cosmology, and the new expressions of contemporary music maintain the communal link between science and art. From earliest times up to the present, we find the same desire to understand and transmit this cultural heritage beyond simple mental construction. It is in this state of scientific criticism and musical sensibility that the 20th century continues. The evolution of the language of physics finds an equal in the language of music with often a deliberate desire of the composer to conserve the link with the harmony of the spheres. Arnold Schoenberg started this movement in 1912 with his Pierrot Lunaire and then with his Transfigured Night. Just as Einstein developed his theories to build up his theory of relativity, so Schoenberg developed in 1923 a new musical language, 12 note theory.

In contemporary music, Karl Heinz Stockhausen (1928-2007) in Tierkreis, Paul Hindemith (1895-1963) in the Harmony of the World, John Cage (1912-1999) in his Atlas Eclipticalis, all deliberately adapt their musical language in order to transcend their cosmic approach and to set out the perfect link between an astronomical subject and its musical commentary. In the Poem of Ecstacy (1908), Alexander Scriabin (1872-1915) triumphantly asserted the profound unity of cosmos and man. Many composers have used the idea of the heavens in different ways with great success. 
In contemporary astronomy, the recurrent questions are to do with cosmological order with particular emphasis on the first moments of the universe as well as on the uncertainties of the future. Large terrestrial and space telescopes can only give a narrow window on our cosmic history but can allow us to learn as well the geometry of the universe and its rhythms. Different vibrations, resulting from primary sources of matter such as chords and superchords as well as final predictions about relativity in research into gravity waves, are progressively coming onto the scene in order to interpret a still unfinished symphony of which we can only see certain fragments. Astronomy is undertaking a work similar to that of the musicologist who is reconstituting a piece of music from a figured bass. It is possible to hear the battery of pulsars giving out their implacable rhythm, like a choir of all the components of the solar system, stellar recitatives being punctuated with the fortissimo of the supernovae as well as the echos emanating from Big Bang. This underlying harmony comprises the essential reality of physics be it in the immensity of the universe or in the smallness of the microscope.

However, numerous probing questions have still only received partial responses. One of the major queries concerns the existence of other life forms such as extra-terrestrial civilisations that emanate from the same cosmic and harmonic source. One of the 51 commissions of the International Astronomical Union is entitled: Bioastronomy: Search for Extraterrestrial Life, and since the beginning of the 60s, different radio-telescopes have been used to send messages towards the nearest stars. Humankind has also wanted to show its desire of making contact with other worlds by putting evidence of our existence on spacecraft that have been sent across the solar system.

On 20th August and 5th September 1977, 2 spacecraft called Voyager each containing a videodisc were launched towards other civilisations wherever they may be in space and time. On each disc were included in the most elementary of languages, binary, 118 photographs of our planet, 90 minutes of Earth noises, as well as greetings in 60 different languages including that of the whale. For the noise bit, wind, rain, volcanic eruptions, footsteps, motors, kisses, animal cries, etc, were all recorded along with the organised noises of Bach, Beethoven, Mozart, Chuck Berry and traditional songs from the people of the world.

The choice of musical harmony as ambassador of our planet to hypothetical extraterrestrial civilisations was not arrived at by chance. It translates, with the help of this frail bottle launched in the intergalactic sea, to the will to establish a kind of union, a true cosmic Esperanto. Voyager 1 is heading towards the constellation of Ophiuchus, whilst Voyager 2 is heading in the direction of Capricorn. In the Little Bear, there is actually a minuscule star, 17 light years away from us: AC+79.3888. In 40000 years, because of its own motion within our Galaxy, this star will be 3 light years from the sun and less than 1 year from the 2 Voyagers. Such a star could be accompanied by planets. Is there intelligent life on a planet in the system $\mathrm{AC}+79.3888$ ? Is it sufficiently evolved to receive the message? Whatever our future, this disc is nevertheless a tangible, perhaps eternal, witness of a civilisation that has tried, in time and space, to get into harmony with the universe through the music of the spheres.

\section{References}

Proust D 2000, L'Harmonie des Sphères, (Paris: Le Seuil) 